\title{
La dimension religieuse des élections de 2018 et l'obscurantisme chrétien de Bolsonaro
}

Morgane Reina

\section{(2) OpenEdition}

Journals

Édition électronique

URL : http://journals.openedition.org/ideas/5385

DOI : 10.4000/ideas.5385

ISSN : 1950-5701

Éditeur

Institut des Amériques

Référence électronique

Morgane Reina, "La dimension religieuse des élections de 2018 et l'obscurantisme chrétien de Bolsonaro », IdeAs [En ligne], 13 | 2019, mis en ligne le 01 mars 2019, consulté le 01 mai 2019. URL http://journals.openedition.org/ideas/5385; DOI : 10.4000/ideas.5385

Ce document a été généré automatiquement le 1 mai 2019

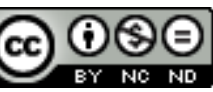

IdeAs - Idées d'Amériques est mis à disposition selon les termes de la licence Creative Commons Attribution - Pas d'Utilisation Commerciale - Pas de Modification 4.0 International. 


\title{
La dimension religieuse des élections de 2018 et l'obscurantisme chrétien de Bolsonaro
}

\author{
Morgane Reina
}

\section{Introduction}

Pour la tradition européenne, héritière de la thèse wébérienne de la séparation des sphères de valeurs conduisant à une professionnalisation et autonomisation des dimensions économique, politique et religieuse de la société, il est parfois difficile d'entendre que la politique et Dieu sont si souvent mêlés, voire confondus. Pour comprendre la constitution de la sphère civile au Brésil, il faut prendre en considération les conditions particulières qui ont présidé à la modernisation du pays. Lors de la séparation de l'Église et de l'État, la religion n'a ni décliné ni été reléguée au monde privé. $\mathrm{Au}$ contraire, elle a activement participé à la construction et à la gestion de l'espace public de débat (Montero P., 2009). Dès lors, la liberté religieuse a entraîné un pluralisme religieux qui a permis aux religions jusqu'alors non officielles de conquérir leur espace dans la sphère politique. C'est ainsi que le protestantisme pentecôtiste qui s'implante dès le début du $\mathrm{xx}^{\mathrm{e}}$ siècle avec l'arrivée de la Congrégation Chrétienne et de l'Assemblée de Dieu sur le sol brésilien, a pu s'affirmer au moment de la reconstitution démocratique de l'État et participer activement à la rédaction de la nouvelle Constitution, après les deux décennies de dictature militaire (1964-1985). Si les différents groupes religieux n'ont pas un projet politique commun clairement structuré, la volonté d'influencer le travail parlementaire pousse les congressistes évangéliques à s'organiser en un Front parlementaire évangélique (Reina, $2018: 3$ ) qui croît jusqu'à atteindre plus d'un tiers de la Chambre basse durant le mandat de 2015-2018 (198 sur 513 députés ${ }^{1}$ ). Composé de députés évangéliques et de députés partageant des valeurs proches, le groupe parlementaire bancada evangélica prend position sur des thématiques sociales, notamment l'égalité de genre, le mariage égalitaire et l'avortement. 
2 L'étude de la dimension religieuse du processus électoral et des premières mesures $d u$ président d'extrême-droite, Jair Bolsonaro, confirme l'importance de la matrice religieuse et des croyances «à même d'informer et de modeler les comportements et les attitudes sociales des populations » (Bastian J.P., 2001 : 135), ainsi que l'instrumentalisation de ces croyances.

\section{L'influence des églises évangéliques dans le scrutin des élections de 2018}

3 Sans nul doute, le pouvoir de mobilisation des églises évangéliques, religion à laquelle appartiennent près d'un tiers des Brésiliens ${ }^{2}$, contribue à expliquer le tournant religieux des élections de 2018 qui ont porté Bolsonaro à la tête du pays et ont provoqué la nette montée en puissance de la bancada evangélica. Le pasteur de l'Assemblée de Dieu, Silas Malafaia, figure importante et radicale du pentecôtisme politique, ainsi que de nombreux autres pasteurs, ont fait montre d'un soutien infaillible au candidat Bolsonaro, notamment en faisant campagne pour lui. Tant l'engagement idéologique que l'imaginaire évangélique fondent leur légitimité dans la recherche d'une nouvelle société au sein de laquelle la préservation des valeurs morales et de la nation "guidée par Dieu » ferait l'objet d'une "guerre spirituelle» (Oro A., 2010: 157). Les premiers résultats de l'enquête de terrain réalisée dans le cadre de notre recherche doctorale ${ }^{3}$ montrent le désir d'une rupture violente et radicale avec le monde (Trœltsch E., 1981) ${ }^{4}$ et le sentiment de persécution ressenti au sein des milieux évangéliques. Cela expliquerait le soutien inconditionnel à un candidat qui revendique la famille traditionnelle, s'oppose à ce qu'il nomme l'idéologie de genre et l'endoctrinement sexuel des enfants à l'école, et apparait in fine comme le seul candidat en mesure de résoudre les problèmes d'insécurité et de violence en proposant la libération du port d'armes. Bolsonaro est considéré comme le représentant de l'autorité considérée nécessaire pour le Brésil, «l'homme moyen », selon l'expression de la journaliste Eliane Brum (Brum E., 2019), le défenseur des intérêts des évangéliques et des croyances autoritaires, sans pour autant faire preuve de véritables compétences pour gouverner.

4 De plus, deux types de stratégies électorales ont permis de mobiliser les bases évangéliques. Premièrement, dans les églises où la condition socioéconomique des membres est très modeste, les fidèles se montrent généralement très réfractaires aux questions politiques. Dans le cadre de leur mission pastorale, les autorités religieuses n'hésitent pas à indiquer directement, au pupitre, pour qui il faut voter. En cas de protestation, les pasteurs peuvent même convoquer les fidèles à la fin du culte en vue de les persuader du bien-fondé de ce choix, comme en ont témoigné certains pasteurs lors d'entretiens réalisés dans le cadre de notre recherche doctorale. Cette méthode de coercition douce apparait donc une méthode d'influence des choix politiques en période électorale. Dans un autre registre, la répétition, dans les prêches, de l'importance du respect des valeurs évangéliques concernant notamment la famille traditionnelle, participe aussi d'un processus de formation aux enjeux politiques et sociaux et engage les fidèles à voter pour le candidat choisi par de nombreux pasteurs.

5 Cet effet Bolsonaro a permis à son parti, le Parti Social Libéral (PSL), de faire élire 52 députés, se constituant ainsi comme le deuxième groupe parlementaire le plus important à la Chambre fédérale 5 . Cependant, le PSL contrôle à peine $10 \%$ des sièges et 
Bolsonaro doit composer avec un Congrès historiquement fragmenté (29 partis représentés). Même si les élections législatives montrent une progression des groupes conservateurs a priori en mesure d'apporter leur soutien au président, celui-ci devra donc tisser des alliances complexes pour pouvoir gouverner, notamment avec le Front Évangélique, qui se pose désormais comme un acteur incontournable, étant donné que le nombre de députés officiellement rattachés à une église évangélique - quel que soit le parti de rattachement - est passé de 84 pour la législature sortante à 91 pour la nouvelle législature (Marini L., A.L. De Carvalho, 2018).

\section{Un discours fondé sur l'omniprésence d'un Dieu punitif}

Que ce soit durant la campagne ou depuis son arrivée au pouvoir, Bolsonaro fait référence au divin dès qu'il en a l'opportunité. Les discours du président sont rythmés par des remerciements à Dieu, ce dernier étant capable d'opérer des miracles comme il le souligne lors de son discours de prise de fonctions le 1er janvier 2019 (Louault F., 2018). Après avoir survécu à une agression à l'arme blanche en pleine campagne électorale, le 6 septembre 2018, il est même devenu un martyr et une idole pour une partie de l'électorat.

7 Tout est dit et décidé au nom de la moralité et de l'autorité d'un Dieu tout puissant, comme le souligne son slogan de campagne, le «Brésil est au-dessus de tout, Dieu audessus de tous ${ }^{6}$ ». L'invocation des principes chrétiens parvient même à justifier une intolérance idéologique et l'exclusion d'éventuels adversaires: «Nous allons unir le peuple, valoriser la famille, respecter les religions et notre tradition judéo-chrétienne, combattre l'idéologie de genre, tout en conservant nos valeurs. Le Brésil sera de nouveau un pays libre d'attaches idéologiques ${ }^{7}$. » De plus, l'incarnation et l'individualisation de la présence de Dieu en la personne de Bolsonaro, comme l'a déclaré le nouveau ministre des Affaires étrangères, Ernesto Araújo, semblent conférer au président une autorité totalisante.

8 De par son baptême dans les eaux du Jourdain en 2016 - alors qu'il s'était toujours considéré comme catholique - la référence incessante à Dieu et le rappel constant aux valeurs chrétiennes durant la campagne, Bolsonaro semble instrumentaliser le religieux, celle-ci apparaissant alors au service d'un agenda ultraconservateur et autoritaire.

\section{Les ministres du noyau des valeurs et l'agenda politique}

Dans une précédente publication, nous avions exploré l'hypothèse d'une institutionnalisation des principes chrétiens et d'exclusion des minorités (Reina, 2016). L'une des conclusions de notre étude révélait que l'entrée d'acteurs pentecôtistes ou néopentecôtistes en politique donnait effectivement lieu à un processus d'inscription des valeurs intolérantes dans le cadre légal. (Reina, 2016: 293) Cette hypothèse semble se confirmer à la suite des élections de 2018, tant « l'intense alignement du gouvernement Bolsonaro avec les évangéliques représente la tentative d'une homogénéisation religieuse dans le pays, à partir du moment où les valeurs conservatrices se confondent avec l'acte de gourverner » (Sudré L., Guimarães J., 2019). Dieu n'est donc pas simplement présent dans le discours, il est aussi inscrit dans le programme politique. 

l'Education (Ricardo Vélez), des Affaires étrangères (Ernesto Araújo), de l'Environnement (Ricardo Salles) et de la Femme, de, la Famille et Droits humains (Damares Alves, qui est également pasteure), constituent le noyau dur de ces valeurs, de par leur appartenance religieuse et leurs prises de positions extrêmement conservatrices (Zanlorenssi G., Almeida R. et Corsalette C., 2018). Ainsi, le ministre des Relations Extérieures considère, dans un article publié en janvier 2019 dans la revue états-unienne New Criterion, que la «Providence divine » a participé à l'élection de Bolsonaro. Il loue cette « foi profonde et sincère » et vante un Brésil où "Dieu est de retour " (Campos Mello P., Fernandes T., 2018). Il affirme de plus que "Dieu sera "dans la diplomatie, dans la politique, partout" " (Arias J., 2019). Autre exemple, au lendemain de sa nomination officielle, Damares Alves scande, dans une vidéo tournée lors de la cérémonie de sa prise de fonctions et publiée sur les réseaux sociaux, qu'une ère nouvelle arrive où les garçons seront traités comme des princes et porteront du bleu alors que les filles seront traitées comme des princesses et porteront du rose (Pains C., 2019). La ministre, qui avait menti sur ses diplômes, s'était défendue en invoquant un "diplôme biblique ", au prétexte de son dévouement à la catéchèse. La nomination de tels ministres et leurs prises de positions ne laissent aucun doute quant à l'emprise du religieux sur l'exécutif.

11 Les mesures prises dès les premiers jours du gouvernement semblent conforter cette hypothèse d'une institutionnalisation des valeurs chrétiennes. Ainsi, au 1er janvier, la mesure provisoire 870 n'inscrivait plus les citoyens LGBT+ comme faisant partie des directives et politiques publiques en matière de promotion des droits de l'Homme. Ne figurant plus parmi les populations vulnérables, elles ne font plus l'objet de politiques publiques spécifiques visant à leur protection, alors que le Brésil est le pays où l'on tue le plus de LGBT+ au monde (Bortoni L., 2018).

12 En promulgant ces mesures décisives, le président élu semble définir les priorités et l'orientation de sa politique gouvernementale, lesquelles menacent les droits et libertés individuels et les minorités au nom d'un universalisme chrétien. Comme le souligne Eliane Brum : le « discours idéologique sert à inculquer la notion de destin et à assurer la cohésion au sein d'une population effrayée par tout ce qu'elle pourrait perdre, des salaires et emplois aux positions symboliques en termes de race, genre et orientation sexuelle» (Brum E., 2019).

\section{BIBLIOGRAPHIE}

Arias, Juan, « O Deus obsessivo e politicamente incorreto de Bolsonaro », El País Brasil,

8 janvier 2019. URL : https://brasil.elpais.com/brasil/2019/01/08/

opinion/1546944981_294288.html

Bastian, Jean-Pierre, « Pluralisation religieuse, pouvoir politique et société en Amérique latine », Pouvoirs, vol. 98, n³, 2001, pp. 135-146. 
Bortoni, Larissa, « Brasil é o país onde mais se assassina homossexuais no mundo », Rádio Senado, 16 mai 2018. URL : https://www12.senado.leg.br/radio/1/noticia/brasil-e-o-pais-que-mais-matahomossexuais-no-mundo

Brum, Eliane, « O homem mediano assume o poder », El País, 4 janvier 2019. URL : https:// brasil.elpais.com/brasil/2019/01/02/opinion/1546450311_448043.html

Brum, Eliane, « He's been president a week - and already Bolsonaro is damaging Brazil », The Guardian, 10 janvier 2019. URL : https://www.theguardian.com/commentisfree/2019/jan/10/jairbolsonaro-brazil-minorities-rainforest ?fbclid =IwAR21Hpd4VU3EWHdNABfHE0JcXZMzluHaNMBjmHEGbBmuvfqMQOER8WFRgY

Campos Mello, Patrícia et Fernandes, Talita, « Providência divina ajudou a eleger Bolsonaro, escreve Ernesto Araújo em revista », Folha de S. Paulo, 31 décembre 2018. URL : https://

www1.folha.uol.com.br/mundo/2018/12/providencia-divina-ajudou-a-eleger-bolsonaro-escreveernesto-araujo-em-revista.shtml

Louault, Frédéric, « Portrait de Jair Bolsonaro, président de la République Fédérative du Brésil », Blog Institut Montaigne, 21 décembre 2018. URL : https://www.institutmontaigne.org/blog/ portrait-de-jair-bolsonaro-president-de-la-republique-federative-du-bresil

Marini, Luisa et Carvalho, Ana Luiza De, « Renovada, bancada evangélica chega com mais força no próximo Congresso ", Congresso em foco, 17 octobre 2018. URL : https://

congressoemfoco.uol.com.br/legislativo/renovada-bancada-evangelica-chega-com-mais-forcano-proximo-congresso/.

Montero, Paula, « Secularização e espaço público : a reinvenção do pluralismo religioso no Brasil », Etnográfica [en ligne], vol. 13, 2009, pp. 7-16. URL : https://www.redalyc.org/articulo.oa? $\mathrm{id}=372339158001$

Oro, Ari Pedro, «Ascension et déclin du pentecôtisme politique au Brésil », Archives de sciences sociales des religions, $\mathrm{n}^{\circ} 149,2010$, pp. 151-168.

Pains, Clarissa, « "Menino veste azl e menina veste rosa”, diz Damares Alves em vídeo », o Globo, 3 janvier 2019. URL : https://oglobo.globo.com/sociedade/menino-veste-azul-menina-veste-rosadiz-damares-alves-em-video-23343024.

Reina, Morgane, « A moralidade segundo os princípios de Deus : a discriminação evangélica contra as populações LGBTTIQ no Brasil ", Anais V CONINTER, Congresso Internacional Interdisciplinar em Sociais e Humanidades, Brasília, 23-25 novembre 2016, pp. 288-297.

Reina, Morgane, «Le miracle pentecôtiste en politique. De la socialisation politique à l'expression démocratique des fidèles au Brésil », Émulations [en ligne], mis en ligne le 18 octobre 2018, pp. 1-16, URL : http://www.revue-emulations.net/enligne/Reina-le-miracle-pentecotiste.

Sudré Lu, Guimarães, Juca, « Posse de Bolsonaro desafia os limites do Estado laico ; entenda », Brasil de Fato, $1^{\mathrm{er}}$ janvier 2019, URL : https://www.brasildefato.com.br/2019/01/01/posse-debolsonaro-desafia-os-limites-do-estado-laico-entenda/

Trœltsch, Ernst, The Social Teaching of the Christian Churches, Chicago, University of Chicago Press, 1981.

Zanlorenssi, Gabriel, Almeida, Rodolfo et Corsalette, Conrado, « A composição dos ministérios no governo Bolsonaro », Nexo Jornal, 31 décembre 2018, URL : https://www.nexojornal.com.br/ grafico/2018/12/31/A-composição-dos-ministérios-no-governo-Bolsonaro 


\section{NOTES}

1. Selon le site de la Chambre des Députés. URL : https://www.camara.leg.br/internet/deputado/ frenteDetalhe.asp?id=53658

2. Selon les estimations réalisées à partir du recensement de 2010 de l'Institut Brésilien de Géographie et de Statistiques (IBGE) et de l'institut de sondage Datafolha, in Chagas, Thiago, "Número de evangélicos não para de crescer», Gospel Mais, 26 de dezembro de 2018, URL : https://noticias.gospelmais.com.br/numero-evangelicos-brasil-nao-para-crescer-

datafolha-87608.html.

3. Enquête réalisée dans le cadre d'une thèse de doctorat en cours, intitulée "Imaginaire religieux et formation des individualités dans le protestantisme pentecôtiste et néopentecôtiste au Brésil » (Université de Brasília).

4. La typologie de Trœltsch montre que les premières églises protestantes - que l'on peut définir de manière plus générique d'évangéliques - surgissent tout d'abord comme des sectes, qui se fondent sur les principes d'ascétisme et de séparation avec le monde. Chez les pentecôtistes classiques, la rupture entre monde physique et monde non phyique est de grande importance. Le monde est rejeté car c'est l'endroit où opère le Diable, au moyen de désirs et tentations comme le plaisir charnel, l'attachement matériel, etc. - surgissent tout d'abord comme des sectes, qui se fondent sur les principes d'ascétisme et de séparation avec le monde.

5. Après le Parti des Travailleurs : 57 députés.

6. Les citations sont traduites en français par l'auteure de cet article.

7. Phrase prononcée lors de son discours de prise de fonctions (https://www1.folha.uol.com.br/ poder/2019/01/leia-a-integra-do-discurso-de-bolsonaro-na-cerimonia-de-posse-nocongresso.shtml).

\section{AUTEUR}

\section{MORGANE REINA}

Doctorante en sociologie à l'Institut de sciences sociales de l'Université de Brasília (PPGSOL/ UnB). Professeure volontaire du département de sociologie de l'Université de Brasília. 